\title{
Variabilidade sazonal no ducto epididimário de codorna doméstica: observações morfológicas ${ }^{1}$
}

\author{
Antônio M. Orsi ${ }^{2 *}$, Raquel F. Domeniconi ${ }^{2}$, Karina Simões ${ }^{2}$, Maíra A. Stefanini ${ }^{3}$ \\ e Silvana M. Baraldi-Artoni ${ }^{4}$
}

\begin{abstract}
Orsi A.M., Domeniconi R.F., Simões K., Stefanini M.A. \& Baraldi-Artoni S.M. 2007. [Seasonal variability in epididymal duct of the domestic quail: morphologic features.] Variabilidade sazonal no ducto epididimário de codorna doméstica: observações morfológicas. Pesquisa Veterinária Brasileira 27(12):495-500. Departamento de Anatomia, Universidade Estadual Paulista, Cx. Postal 510, Botucatu, SP 18618-000, Brazil. E-mail: amorsi@ibb.unesp.br

Small but expressive variability was noted on the epididymidis duct (ED) of domestic quail along the year, with more evidence in autumn of the quiescent phase of the annual testis cycle in this species. Spring features of ED had a general similar pattern in summer and winter. They were characterized by enlargement of epididymis tubule, storage of spermatozoa into the luminal compartment and presence of mitochondria, ER lamellae, several variable vesicles, and lysosomes localized mainly on the apical cytoplasm of principal cells $(\mathrm{P})$ of the epididymal epithelium. These $\mathrm{P}$ cells features indicated a process of endocytosis and perhaps protein secretion. Autumn quiescence was marked by a convolute pattern of the epididymis tubule, lacking of spermatozoa and small amount of exfoliate heterogeneous material inside the luminal compartment at light microscopy. Ultrastructural degenerative features mainly apical cytoplasmic debris were seen in the supranuclear cytoplasm of lining P cells.
\end{abstract}

INDEX TERMS: Epididymidis duct, morphology, seasonal variability, quail.

RESUMO.- $O$ ducto epididimário (DE) de codorna doméstica mostrou, ao longo do ano, variabilidade pequena, porém muito expressiva no outono, o qual corresponde à fase quiescente do ciclo testicular anual. A morfologia do DE na primavera foi, em termos, similar à verificada no verão e inverno. Nestas fases notaram-se aumento significante do calibre tubular do DE; estocagem intraluminal de espermatozóides e ocorrência de mitocôndrias, lamelas do RE, vesículas variáveis quanto à forma, dimensões e conteúdos e presença de alguns lisossomos localizados, principalmente, no citoplas-

\footnotetext{
${ }^{1}$ Recebido em 16 de maio de 2007.

Aceito para publicação em 3 de dezembro de 2007.

${ }^{2}$ Depto Anatomia, Instituto de Biociências, Universidade Estadual Paulista (Unesp), Distrito Rubião Junior s/n, Cx. Postal 510, Botucatu, SP 18618-000, Brasil. "Autor para correspondência: amorsi@ibb,unesp.br

${ }^{3}$ Depto Morfologia e Patologia, Universidade Federal de São Carlos (UFSCar), Rod. Washington Luiz, Km 235, Cx. Postal 676, São Carlos, SP 13565-905, Brasil.

${ }^{4}$ Depto Morfologia e Fisiologia Animal, Faculdade de Ciências Agrárias e Veterinárias (FCAV), Universidade Estadual Paulista (Unesp), Campus de Jaboticabal, Rod. Prof. Paulo Donato Castelane, Km5, Jaboticabal, SP 14884900, Brasil.
}

ma apical das células principais (P), no epitélio epididimário. Estas características ultra-estruturais das células $\mathrm{P}$ parecem ser indicativas da ocorrência de processos ativos de endocitose e de secreção micromerócrina. A quiescência outonal foi caracterizada pelo aspecto anfractuoso do DE; ausência de espermatozóides e pouco material intraluminal, observados à microscopia de luz. Características ultra-estruturais degenerativas foram verificadas ao nível do citoplasma supranuclear das células $\mathrm{P}$ epididimárias no outono.

TERMOS DE INDEXAÇÃO: Ducto epididimário, morfologia, variabilidade sazonal, codorna.

\section{INTRODUÇÃO}

No epitélio do ducto epididimário (DE) de aves predominam as células colunares principais $(\mathrm{P})$, não ciliadas, que aparentam ter correspondência morfológica com as células principais dos dúctulos eferentes distais, nesta classe de vertebrados (Tingari 1972). Em termos funcionais, aparentemente, o DE de aves equivaleria à cabeça do epidídimo de mamíferos e o ducto deferente, nesta classe, corresponderia ao corpo e à cauda epididimários de mamíferos (Tingari 1971, De Reviers 1975). Ademais, haveria pequena participação do DE em aves 
no processo de maturação intraluminal dos espermatozóides (Clullow \& Jones 1982, Howarth 1983), sendo que na luz do ducto deferente é onde efetivamente ocorreria a maturação gamética (Howarth 1983, Stefanini et al. 1996, Stefanini et al. 1999a,b).

As células $P$ do epitélio tubular do DE em aves, aparentemente, são menos ativas, histofisiologicamente, do que as correspondentes células P dos dúctulos eferentes nesta classe (Hess \& Thurston 1977, Stefanini et al. 1999a,b). Contudo, apesar de parecer ser modesto o papel das células P no DE de aves, e, conseqüentemente, a relevância funcional do próprio DE concernente ao que se cumpre histofisiologicamente nos compartimentos epitelial e luminal dos ductos excretores dos testículos, neste filo, afirmou-se, para o galo doméstico, que os espermatozóides permanecem 30 minutos na luz dos dúctulos eferentes e 80 minutos na luz do DE (Clullow \& Jones 1982, 1988).

Logo, aquela permanência maior dos espermatozóides em trânsito no DE de galo é sugestiva de que papéis tróficos e funcionais devam se cumprir na inter-relação dinâmica entre os espermatozóides na luz e as células P no epitélio de revestimento do DE de aves, ao menos em nível teórico, mas com forte embasamento no que ocorre efetivamente nas inter-relações entre os compartimentos epitelial e luminal do epidídimo de aves (Hess \& Thurston 1977, Clullow \& Jones $1982,1988)$ e nos mamíferos. Nesses os papéis funcionais da habilitação de fertilização dos espermatozóides foram bem evidenciados (Robaire \& Hermo 1984, Hermo et al. 1994).

Quanto ao comportamento reprodutivo sazonal de aves, inclusive na codorna doméstica da variedade italiana, na qual aqui é enfocado o DE, previamente se observaram os menores valores para as variáveis alturas do epitélio de revestimento; diâmetro tubular e diâmetro luminal do ducto deferente nos meses de outono, principalmente entre meados de março e meados de abril (Orsi et al. 2002). Estes dados se completaram com estudos sobre a dinâmica do ciclo testicular nesta espécie, durante as estações do ano, em que se verificou o menor índice gonadossomático (IGS = massa testicular/massa corpórea), no período outonal (Orsi et al. 2005).

Além disso, no curto período outonal se observou parada do processo espermatocitogenético, em termos de não evoluir completamente a cinética da espermatogênese e, em consequiência, a espermiação de espermatozóides (Orsi et al. 2005). Por outro lado, nos períodos enfocados nos meses de inverno, primavera e verão a espermatogênese se manteve ativa na codorna "italiana", com acompanhamento compatível do IGS, permitindo-se estabelecer 4 fases sequientes: quiescente (parada outonal), recrudescente (retomada invernal), proliferativa (atividade plena primaveril) e regressiva (recesso no verão). Estas fases tenderiam a se repetir ao longo do ano, em face das observações morfológicas, obtidas, em idênticos períodos do ano, aos níveis dos ductos deferentes e dos testículos, respectivamente, as quais foram compiladas em 2 anos não seqüientes (Orsi et al. 2002, 2005).

Na variedade japonesa de codorna doméstica (Coturnix coturnix japonica) foi postulado um comportamento testicular anual cíclico, sendo as fases do ciclo diferentes em termos de atividades espermatogenéticas e dos períodos (estações) do ano (Artoni et al. 1997), dos achados que se obtiveram na variedade italiana de Coturnix coturnix (Orsi et al. 2005). Discutiram-se então as possíveis causas ou razões para tanto, tendo sido ressaltadas possíveis influências do confinamento das codornas "italianas", em condições experimentais (vide Material e Métodos), onde se ressaltavam o equilíbrio de alternância das horas de claro e escuro, bem como que as codornas machos (aqui estudadas) e fêmeas, da mesma variedade, ficaram em contato visual e sonoro, durante o período experimental, porém sem ocorrência de acasalamento (Orsi et al. 2005).

Em face dos resultados obtidos nos estudos anteriores, aos níveis dos ductos deferentes (Orsi et al. 2002) e dos túbulos seminíferos dos testículos (Orsi et al. 2005), objetivou-se estudar os dúctulos da região epididimária (RE) da codorna italiana, e suas possíveis variações sazonais ao longo do ano, acompanhando talvez as características sazonais vistas no testículo. Caracterizar as fases do ciclo, e suas implicações morfológicas, ou morfofuncionais, nos ductos extratesticulares, merece destaque. Isto até porque, para Aire (2002), nas células $\mathrm{P}$ epididimárias, durante o repouso do ciclo anual de algumas aves estudadas, foram notadas desorganização do complexo de endomembranas (RE) e picnose nuclear, sem fazer qualquer outra descrição mais abrangente das demais características do ciclo reprodutivo, naquelas aves.

Assim sendo, houve destaque para estudos do DE de codorna italiana, visto que os túbulos espermáticos de aves concentram-se especificamente nesta região, compreendendo, seqüiencialmente: uma parte da rede testicular, os dúctulos eferentes proximais e distais, os ductos conectados e o DE, o qual, por sua vez, se continua ao ducto deferente localizado, caudalmente e externamente à RE nesta classe (Tingari 1971,1972, Stefanini et al. 1999b, Aire 2002).

\section{MATERIAL E MÉTODOS}

Vinte e quatro codornas (Coturnix coturnix), da variedade italiana, machos, sexualmente maduras, ficaram confinadas em criatório de pesquisa, junto à Fazenda de Experimentação Biológica, "Edgardia", da Unesp em Botucatu, durante um ano. Permaneceram no cativeiro experimental recebendo dieta sólida normal para aves (Purina ${ }^{\mathrm{TM}}$, Brasil) e água, administradas ad libitum, e sob condições de iluminação predominantemente natural. Assim sendo, foram submetidas a aproximadamente 12 horas de claro e 12 horas de escuro, permanecendo separadas, em gaiolas vazadas de criatório, de plantéis similares de fêmeas da mesma espécie e variedade, igualmente confinadas. Portanto, as aves de ambos os sexos ficaram em contato visual e sonoro, neste período, porém sem ocorrência de acasalamento.

Posteriormente, no decorrer do ano seguinte, os machos foram transportados em grupos de 6 codornas, durante os meses mais expressivos de verão (janeiro e meados de fevereiro); outono (meados de março e abril); inverno (junho e meados de julho), e, primavera (meados de outubro e primeira quinzena de novembro), para os laboratórios de Anatomia e Morfologia Microscópica do Instituto de Biociências da Unesp em Botucatu, onde se obteve eutanásia das aves por meio de saturação anestésica com a mistura de XylazinaKetamina ${ }^{\circledR}$. A seguir foram feitas laparotomia; evisceração do trato gastrointestinal e coleta bilateral dos testículos e região epididimária 
(RE) das codornas. Fragmentos dos materiais coletados foram fixados nos fixadores histológicos de formalina tamponada, em tampão fosfato, $\mathrm{pH}$ 7,2, $0.1 \mathrm{M}$ e líquido de Bouin, para estudos de microscopia de luz de materiais processados em paraplast ${ }^{\mathrm{TM}}$ (Oxford Labware, EUA), e em soluções de Karnovsky e de McDowell, para materiais destinados à rotina de historesina (Historesin ${ }^{\circledR}$, Leica, Alemanha). $\mathrm{O}$ material fixado em solução de Karnovsky, a partir de coletas feitas em outras quatro aves, dois no outono e dois na primavera, foram processados para microscopia eletrônica de transmissão (MET), objetivando prosseguimentos subseqüentes dos estudos.

Para microscopia de luz os fragmentos foram incluídos em paraplast $^{\mathrm{TM}}$ e/ou em historesin ${ }^{\mathrm{O}}$; microtomia (cortes de 1,5-5mm) e coradas com HE, tricrômico de Masson-Goldner, PAS/H, hematoxilina/ floxina e solução de azul de toluidina a $0,5 \%$ destinando-se estes materiais para estudos em microscópios de pesquisas Olympus BH2 e $\mathrm{BX}-40^{\mathrm{O}}$ (Olympus, Japão). Estudos histomorfométricos do DE, nas quatro estações do ano, foram realizados com a utilização de sistemas de análise de imagens (Optimas 4.10 IBM, Zeiss KS-300).

Os dados morfométricos foram obtidos com o uso de ocular micrométrica adaptada ao microscópio Olympus BH-2. Análises histomorfométricas foram feitas, visando-se obter os valores médios de alturas epiteliais e dos diâmetros tubulares e luminais do DE. Para as mensurações destes parâmetros foram utilizadas três lâminas de cada animal, contendo as lâminas três cortes histológicos com quatro medidas por corte. As mensurações das seç̧ões tubulares, com contornos preferencialmente transversais, foram feitas contornando-se os túbulos na base do epitélio, ao nível da membrana basal, para obtenção do diâmetro tubular total, e junto à borda apical de estereocílios para obtenção do diâmetro luminal, utilizando-se objetiva de 10x. De modo similar, utilizando-se objetiva de 40x, foi mensurada, linearmente, a altura do epitélio epididimário, referida como o comprimento das células principais desde a sua base até a borda apical de estereocílios. Os valores médios das medidas foram fornecidos pelo próprio programa. Os resultados foram agrupados por estações do ano e tratados estatisticamente por métodos paramétricos, ou seja, com cálculos dos valores de médias aritméticas; desvios padrão e análises de variância (Morrison 1976).

Os fragmentos destinados a MET foram pós-fixados em tetróxido de ósmio a 1\% em tampão fosfato de sódio pH 7,2, $0.1 \mathrm{M}$, durante 1 hora a $4^{\circ} \mathrm{C}$. Os fragmentos tissulares foram desidratados em série crescente de acetona, incluídos em Araldite ${ }^{\mathrm{ò}}$ (Merck, Alemanha) e submetidos à ultramicrotomia (cortes de $80 \mathrm{~nm}$ ). Os cortes ultrafinos obtidos foram montados em grades de cobre; contrastados com acetato de uranila e citrato de chumbo, analisados e documentados fotograficamente em ME Philips CEM $100^{\circ}$ (Philips, Holanda).

\section{RESULTADOS}

O ducto epididimário (DE), observado na região epididimária de codorna da variedade italiana, é um túbulo alongado e ondulado, tendo epitélio de revestimento pseudoestratificado (Fig.1a-d). Apresenta células epiteliais principais (P) não
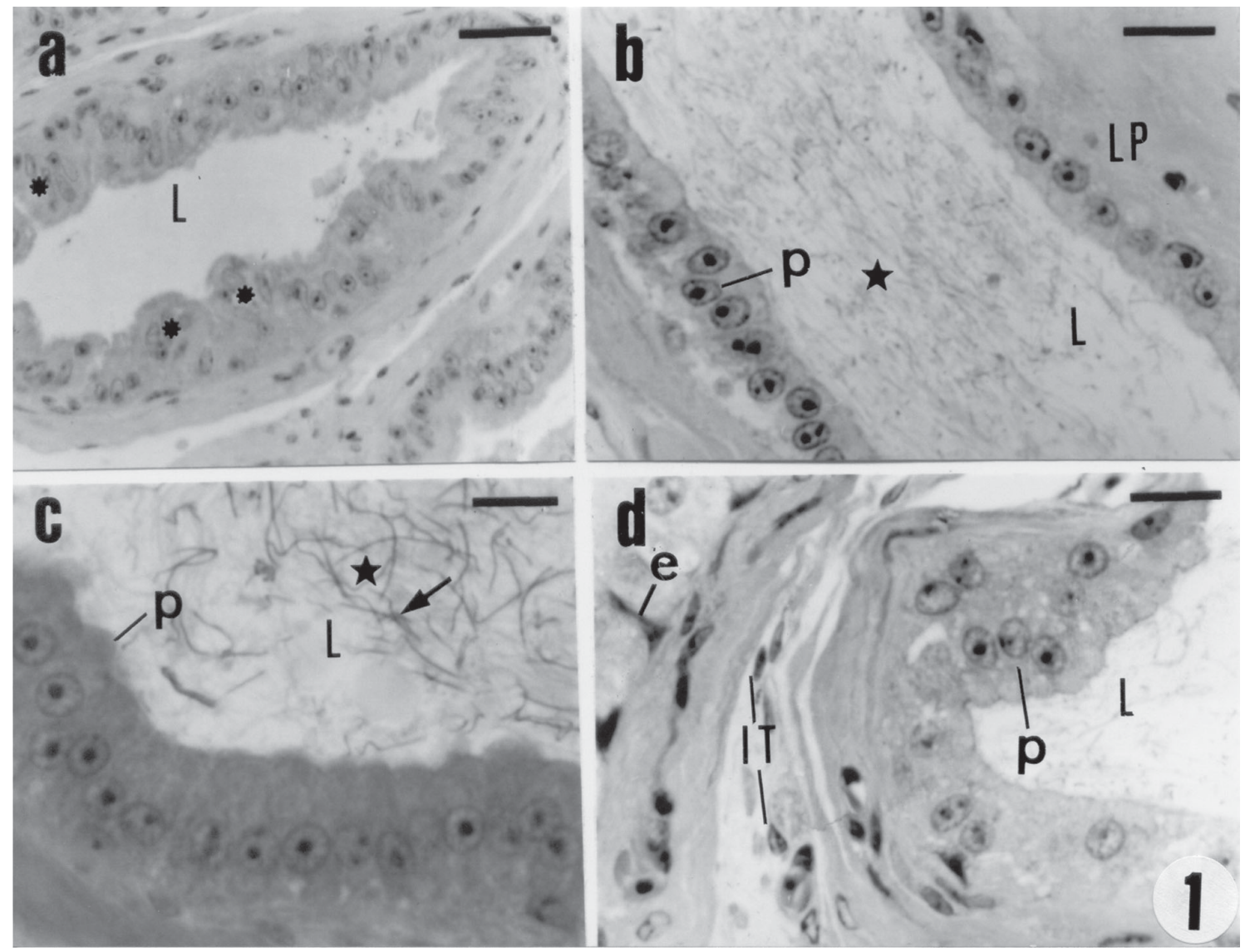

Fig,1. Secções histológicas do ducto do epidídimo (DE) de codorna doméstica da "variedade italiana", com orientação predominantemente transversal, sendo indicados: lúmen tubular (L), vilosidades no epitélio (asterisco, em a), material intraluminal (estrela, em b,c) inclusive espermatozóides (seta, em c), células do epitélio tubular principais (p) e escura (e), lâmina própria tubular (LP) e interstício tubular. a) Fases

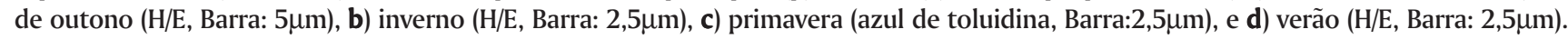




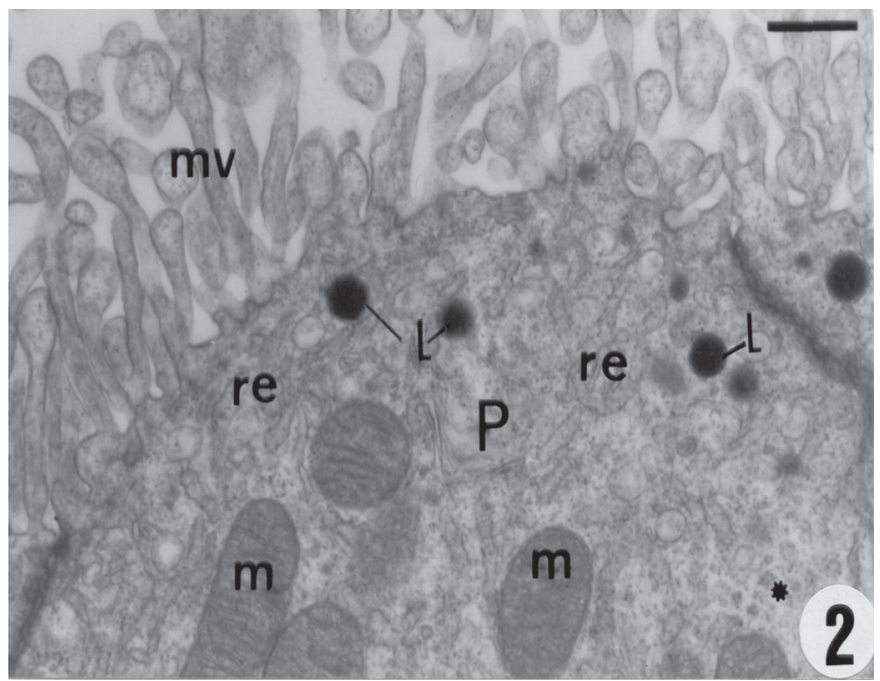

Fig.2. Ultraestrutura do citoplasma apical de uma célula principal $(\mathrm{P})$, sendo indicados: microvilos periluminais (mv), cisternas lamelares e vesiculares do complexo RE supranuclear (re), polissomos (asterisco), lisossomos (L) e mitocôndrias (m). Seç̧ão transversal de DE na fase de inverno. Barra: $0,44 \mu \mathrm{m}$.

ciliadas, ou seja, dotadas de microvilos apicais e ausência de "cinetocílios" (cílios verdadeiros), como se caracteriza nitidamente, ao nível ultraestrutural, na borda luminal das células $P$ do DE no inverno (Fig.2).

No outono, durante a fase quiescente do ciclo testicular anual desta ave (Orsi et al. 2005), o epitélio tubular epididimário, preponderantemente constituído por células P, aparece mais anfractuoso, tendo "vilosidades" e criptas contíguas que conferem à luz tubular um aspecto irregular. Os núcleos das células $P$ aparecem mais aglomerados e superpostos, talvez em consequiência da aparência "vilosa" do epitélio tubular (Fig.1a).

A luz tubular do DE no outono aparece predominantemente vazia, observando-se pouco material heterogêneo e ausência de espermatozóides intraluminais. A borda luminal das células $P$ do epitélio de revestimento do DE, neste período, mostra-se mal definida, notando-se aparente ausência de microvilos (estereocílios) apicais em microscopia de luz (Fig.1a).

A última observação se confirma ao nível ultraestrutural, em que o citoplasma apical da maioria das células $\mathrm{P}$ sofre uma expansão degenerativa apical, perdendo-se em algumas células partes expressivas do citoplasma com a borda de microvilos, ou se notando delimitação plasmalemal de áreas citoplasmáticas apicais com conteúdo de organelas; talvez em processo de extrusão para o lúmen tubular. A eletrondensidade núcleo-citoplasmática é baixa, e as poucas organelas citoplasmáticas presentes, como as mitocôndrias, lisossomos e lamelas do RE mostram características degenerativas (Fig.3a).

$\mathrm{O}$ aspecto tortuoso do epitélio tubular do ducto epididimário no outono decorre, aparentemente, da típica redução dos valores médios dos diâmetros do ducto e da luz tubular, neste período, embora os valores médios da altura epitelial não tenham mostrado variação significante, comparativamente às outras estações do ano (Fig.4). A lâmina própria tubular, predominantemente conjuntiva densa, é circundada pelo interstício tubular conjuntivo frouxo disposto entre as secções tubulares adjacentes (Fig.1a).

No inverno, que caracteriza a fase recrudescente do ciclo testicular anual da codorna "italiana" (Orsi et al. 2005), o epitélio do DE apresenta um maior alinhamento dos núcleos das células $P$. Aparentemente, é menor a faixa do citoplasma supranuclear, embora o padrão pseudoestratificado do epitélio seja mantido. A luz do DE aparece preenchida por formações heterogêneas e exibe maior quantidade de espermatozóides (Fig.1b).

Na primavera, a fase proliferativa do ciclo testicular de codorna italiana (Orsi et al. 2005), o citoplasma das células P do epitélio epididimário tem eosinofilia marcante. Os núcleos são
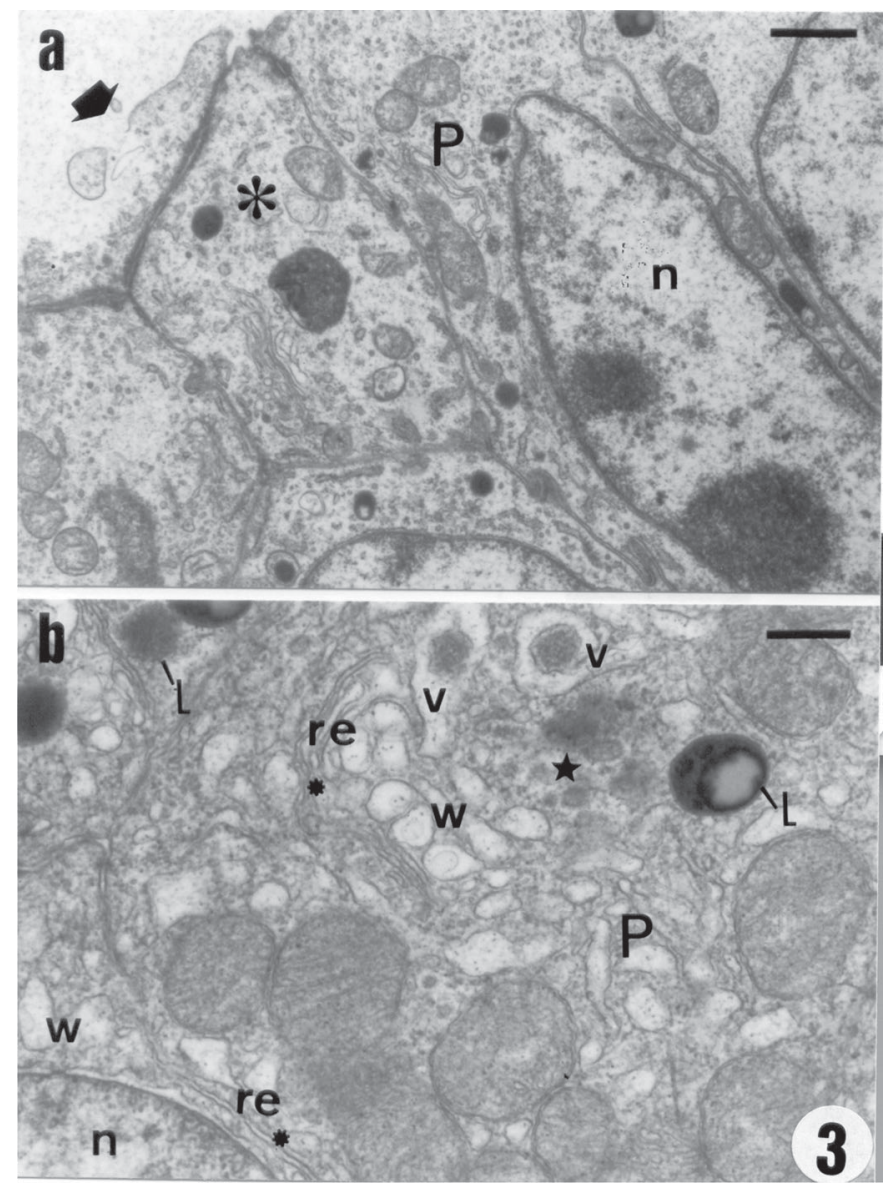

Fig.3. Ultraestrutura do citoplasma supranuclear de células $\mathrm{P}$ do DE, com orientação predominantemente transversal dos cortes ultrafinos $(80 \mathrm{~nm})$, nas fases de outono (a. Barra: $0,75 \mu \mathrm{m})$ e de primavera (b. Barra: $0,32 \mu \mathrm{m}$ ). São caracterizados aspectos citoplasmáticos degenerativos (asteriscos) das organelas e do padrão cromatínico nuclear (n) e processo expansivo do citoplasma apical "debridado" (seta espessa) na luz tubular (em a). São apontados núcleo (n), cisternas do retículo endoplasmático (re): lamelares (asteriscos) e vesiculares (w); vesículas revestidas de conteúdo denso (v), região de vesículas menores compactamente eletrondensas (estrela), lisossomos (L) e mitocôndrias (m), (em b). 
arredondados, e dispostos de modo similar aos observados no inverno. O nucléolo é geralmente único e a cromatina é predominantemente granular. Na base do epitélio podem ser vistos poucos núcleos piramidais de células basais. Dentro da luz tubular encontram-se muitos espermatozóides, alguns dos quais se aproximam da borda apical de microvilos. 0 estroma peritubular é formado por tecido predominantemente conjuntivo denso, com núcleos de fibroblastos evidentes (Fig.1c).

Ao nível ultraestrutural o citoplasma supranuclear das células $\mathrm{P}$ do DE em codorna "italiana", na primavera, mostra predomínio de estruturas subcelulares do RE-granular, com disposições lamelar e vesicular, estando as lamelas e vesículas arranjadas em colunas ou de modo semicircular. Estruturas associadas ao RE como os polissomos e vesículas com diferentes formas, dimensões e conteúdo também ocorrem. A presença de vesículas pequenas revestidas, com conteúdo eletrondenso, e de vesículas grandes internalizando material também denso, adjacentes a aglomerados de mitocôndrias arredondas, é indicativa de ocorrência de processos ativos de secreção protéica, conforme discussão posterior. Pouca quantidade de lisossomos apicais é também vista, com formações vesiculares adjacentes (Fig.3b). A ultraestrutura das células $P$ do $\mathrm{DE}$ no inverno não mostra diferenciação citoplasmática apreciável (Fig.2), em relação a estas mesmas células descritas na primavera.

No verão, durante a fase regressiva do ciclo testicular anual da codorna "italiana" (Orsi et al. 2005), ocorre um maior espaçamento relativo entre os núcleos das células $\mathrm{P}$ do ducto epididimário, sendo que os núcleos tendem a se dispor em diferentes alturas na estrutura epitelial, notando-se também células delgadas escuras e células basais pouco freqüentes. $O$ predomínio das células $\mathrm{P}$ e a posição centralizada de seus núcleos são notórios, e a luz tubular tem pouco conteúdo intraluminal de espermatozóides (Fig.1d). Entretanto, as características ultraestruturais básicas do citoplasma das células $P$ no verão são similares às observadas no inverno (Fig.2) $\mathrm{e}$ na primavera (Fig.3b).

Altura do epitélio, diâmetro da luz e do ducto epididimário de codorna durante o ciclo reprodutivo anual

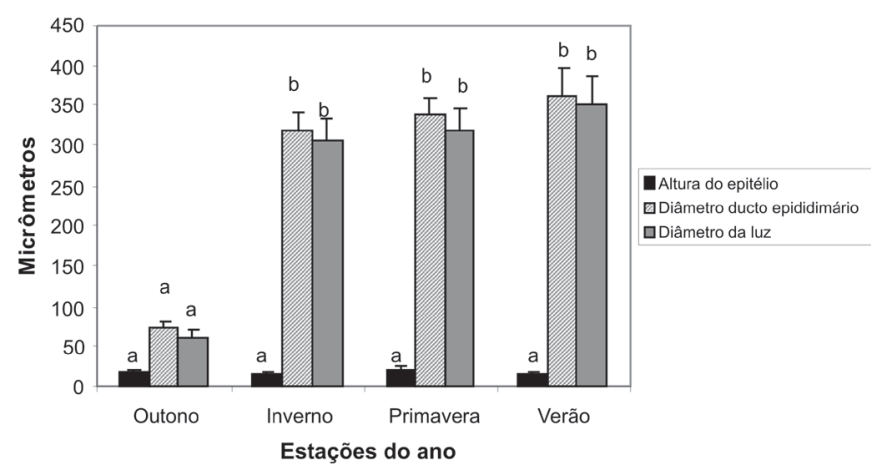

Fig.4. Histograma representativo dos valores numéricos médios de altura do epitélio epididimal, diâmetro tubular e diâmetro luminal, do DE em codorna "italiana", relacionados com a variabilidade sazonal nas estações de outono, inverno, primavera e verão, respectivamente.
Os valores médios dos diâmetros tubular e luminal, no ducto epididimal de codorna, são relativamente grandes tanto na primavera quanto no verão e inverno, não sendo significativamente diferentes entre si, dentro de cada estação, e nem entre estas três estações do ano, quando comparados entre si. $\mathrm{O}$ ducto epididimário sofre, contudo, efetiva redução de calibre tubular no outono, sendo significativamente menor, conforme já foi relatado. Os valores médios de altura do epitélio tubular epididimal não mostram variações significativas nas quatro estações do ano (Fig.4).

\section{DISCUSSÃO}

Quanto às observações histomorfométricas do ducto epididimário (DE) de codorna da variedade italiana, ao longo do ano, foi verificado que os valores médios dos diâmetros tubular e luminal se eqüivaleram nas estações de primavera, verão e inverno. Assim não se observaram diferenças expressivas entre ambos os diâmetros quando comparados entre si dentro das estações, ou mesmo entre estas estações do ano. Apenas no outono, entre meados de março e abril, caracterizaram-se diminuições expressivas e significativas dos diâmetros tubular e luminal do DE. Estas observações foram notadas de modo similar à acentuada diminuição do índice gonadossomático, bem como à parada do processo espermatocitogenético, observados na codorna "italiana", no outono, (Orsi et al. 2005), com aparente reflexo direto sobre a histofisiologia dos ductos "excretores" do testículo, como o DE aqui enfocado.

Concernente ao epitélio epididimal, este se mostrou pseudoestratificado colunar e com microvilos apicais na fase ativa primaveril, e nas fases intermediárias, mas igualmente ativas, no verão e inverno, em termos da cinética testicular (Orsi et al. 2005), não ocorrendo diferenças histomorfo-métricas expressivas na altura epitelial do DE em todas as estações, inclusive no outono. Porém, nesta estação a borda apical de microvilos das células principais $(\mathrm{P})$ foi de difícil caracterização, à microscopia de luz e ao nível ultraestrutural, conforme as observações aqui feitas.

Ultraestruturalmente, no citoplasma apical da maioria das células $\mathrm{P}$, no epitélio de revestimento do DE da codorna "italiana", no outono, verificou-se um processo degenerativo citoplasmático com debridamento de partes expressivas do citoplasma apical e dos microvilos. Houve aparente processo de extrusão de organelas para o lúmen tubular; baixa eletrondensidade núcleo-citoplasmática, e características degenerativas das poucas organelas presentes no citoplasma apical (vide Fig.3a). Estas observações, resguardadas as peculiaridades espécie-específicas, foram similares às descritas em células $P$ dos dúctulos eferentes epididimários do esquilo Citellus lateralis durante a fase regressiva do ciclo testicular anual deste mamífero (Pudney \& Fawcett 1984).

O padrão histológico geral do epitélio epididimal ativo de codorna foi, em linhas gerais, similar ao verificado em outras aves sexualmente ativas (Aire 2002), embora poucos microvilos foram evidenciados na borda luminal de células epididimárias ativas do pombo doméstico (Stefanini \& Orsi 1999, Stefanini et al. 1999b). Por outro lado, as características degenerativas marcantes do epitélio epididimal de codor- 
na no outono, sem relato similar noutras aves, talvez fizesse parte de um processo de "renovação" celular epitelial nesta fase quiescente do ciclo testicular anual.

Aparentemente, as características ultraestruturais degenerativas das células P outonais, no DE de codorna "italiana", visariam à reciclagem e recuperação destas células epiteliais na fase subsequente de recrudescência invernal. Assim, se objetivaria retomar paulatinamente o processo de condução epididimária dos espermatozóides já no inverno, o qual cessa no período quiescente de outono. Porém, a condução gamética deve ocorrer com maior plenitude na primavera. Essa é a fase proliferativa do ciclo testicular, previamente, caracterizado como circanual nesta espécie (Orsi et al. 2005).

Em nível teórico, a reciclagem epitelial de células $\mathrm{P}$, no $\mathrm{DE}$ de codorna "italiana", na fase de recrudescência invernal do ciclo, corresponderia ainda ao restabelecimento de inter-relações tróficas e funcionais das células $\mathrm{P}$ com os espermatozóides, à semelhança do que se discutiu para o roedor Citellus lateralis (Pudney \& Fawcett 1984), resguardadas obviamente as características espécie-específicas.

De modo geral, aparentemente, haveria uma modesta participação do ducto epididimal de aves no processo de maturação intraluminal dos espermatozóides (Clullow \& Jones 1982, Howarth 1983), sendo que é na luz do ducto deferente que efetivamente ocorreria a maturação de espermatozóides (Howarth 1983, Stefanini \& Orsi 1999). Logo, no ducto epididimal de aves ocorreriam funções similares às caracterizadas nos segmentos tubulares da cabeça epididimal de mamíferos (Tingari 1971, De Reviers 1975, Stefanini et al. 1999b), as quais foram extensivamente detalhadas, especialmente no epidídimo de roedores laboratoriais, em relevantes revisões monográficas (Robaire \& Hermo 1988, Hermo et al. 1994).

Apesar das considerações anteriores de Clullow \& Jones (1982) e Howarth (1983), a observação de alguns lisossomos relacionados a complexos vesiculares e mitocôndrias, presentes no citoplasma de células $\mathrm{P}$ do epitélio epididimário de Coturnix coturnix, leva a pressupor, efetivamente, a ocorrência de atividade endocitótica. Essa foi similar à descrita em células P do DE em mamíferos (Hermo et al. 1994), e de ocorrência, talvez simultânea, de atividade de digestão celular heterofágica relatada para células P do DE em outras aves (Aire 2000).

Agradecimentos.- Ao CNPq pelo auxílio acadêmico (Proc.30.1242/80 RN, Demanda de 2000); à FAPESP pelo apoio financeiro institucional (Proc.03/008790, Período 2003-2005), referentes a este estudo; e ao Centro de Microscopia Eletrônica, Unesp-Botucatu, pelo trabalho especializado e eficaz.

\section{REFERÊNCIAS}

Aire T.A. 2000. Aspects of the functional morphology of the ductus epididymidis in domestic anseriform and galliform birds. Anat. Histol. Embryol. 29:179-191.
Aire T.A. 2002. Cyclical reproductive changes in the non-ciliated epithelia of the epididymis of birds. Anat. Histol. Embryol. 31:113-118.

Artoni S.M.B., Orsi A.M., Carvalho T.L.L. \& Lopes R.A. 1997. The annual testicular cycle of the domestic quail (Coturnix coturnix japonica). Anat. Histol. Embryol. 26:337-339.

Clullow J. \& Jones R.C. 1982. Production, transport, maturation, storage and survival of spermatozoa in the male japanese quail (Coturnix coturnix). J. Reprod. Fertil. 64:259-266.

Clullow J. \& Jones R.C. 1988. Studies of fluid and spermatozoal transport in the extratesticular genital duct of the japanese quail. J. Anat. 157:1-11.

De Reviers M. 1975. Sperm transport and survival in male birds. In: The Biology of Spermatozoa. Karger, Basel. (Cit. Orsi et al. 2005)

(ed.),

Hermo L., Oko R. \& Morales C. 1994. Secretion and endocytosis in the male reproductive tract: a role in sperm maturation. Int. Rev. Cytol. 154:105189.

Hess R.A. \& Thurston R.J. 1977. Ultrastructure of the epithelial cells in the epididymal region of the turkey (Meleagris gallopavo). J. Anat. 124:765-778.

Howarth B. 1983. Fertilizing ability of cock spermatozoa from the testis, epididymis and vas deferens after intramarginal insemination. Biol. Reprod. 28:589-590.

Morrison D.F. 1976. Multivariate Statistical Methods. Kogakusha, Tokyo. (Cit. Stefanini \& Orsi 1999)

Orsi A.M., Cruz C., Viegas K.A.S., Machado M.R.F., Domeniconi R.F., Simões K. \& Artoni S.M.B. 2002. O ducto deferente de codorna: estrutura e possíveis variações morfológicas sazonais. Anais XX Congr. Bras. Anatomia, Maceió, Alagoas, p.159.

Orsi A.M., Stefanini M.A., Viegas K.A.S., Simões K. \& Artoni S.M.B. 2005. Aspectos morfológicos do ciclo testicular anual de codorna doméstica (Coturnix coturnix) da variedade italiana. Braz. J. Vet. Res. Anim. Sci. 42:163170.

Pudney J. \& Fawcett D.W. 1984. Seasonal changes in fine structure of the ductuli efferentes of the Ground Squirrel, Citellus lateralis. Anat. Rec. 208:383-399.

Robaire B. \& Hermo L. 1988. Efferent ducts, epididymis, and vas deferens: structure, functions, and their regulation, p.999-1080. In: Knobil E.Y. \& Neill J.D. (ed.), The Physiology of Reproduction. Vol.1. $2^{\text {nd }}$ ed. Raven Press, New York.

Stefanini M.A. \& Orsi A.M. 1999. Características morfológicas da região epididimária do pombo doméstico (Columba livia). Braz. J. Vet. Res. Anim. Sci. 36:66-71.

Stefanini M.A., Vicentini C.A., Orsi A.M., Vicentini I.B.F. \& Artoni S.M.B. 1996. Características morfológicas do ducto deferente do pombo (Columba livia). Revta Bras. Biologia 56:605-612.

Stefanini M.A., Orsi A.M., Gregório E.A., Viotto M.J.S. \& Artoni S.M.B. 1999a. Morphologic study of the efferent ductules of the pigeon (Columba livia). J. Morphol. 242:247-255.

Stefanini M.A., Orsi A.M., Crocci A.J., Padovani C.R., Vicentini C.A. \& Aires E.D. 1999b. La región epididimária de la paloma (Columba livia): análisis morfológico y morfométrico. Revta Chil. Anat. 17:21-25.

Tingari M.D. 1971. On the structure of the epididymal region and Ductus deferens of the domestic fowl (Gallus domesticus). J. Anat. 109:423-435.

Tingari M.D. 1972. The fine structure of the epithelial lining of the excurrent duct system of the testis of the domestic fowl (Gallus domesticus). Qt. J. Exp. Physiol. 57:271-295. 